\title{
Assessment of COVID-19 vaccine hesitancy among undergraduate medical students of a tertiary care teaching hospital, Surat: a source of profound concern
}

\author{
Awani Y. Shah*, Neeta Banzal, Chaitali Mehta, Anupama Desai
}

Department of Pharmacology, Surat Municipal Institute of Medical Education and Research, Surat, Gujarat, India

Received: 31 May 2021

Revised: 26 June 2021

Accepted: 29 June 2021

*Correspondence:

Dr. Awani Yogesh Shah,

Email: awaniyshah@gmail.com

Copyright: (C) the author(s), publisher and licensee Medip Academy. This is an open-access article distributed under the terms of the Creative Commons Attribution Non-Commercial License, which permits unrestricted non-commercial use, distribution, and reproduction in any medium, provided the original work is properly cited.

\begin{abstract}
Background: The discussion around COVID-19 vaccines has been in the limelight ever since the announcement was made for mass vaccination campaign in India. Less is known about undergraduate medical students' perception and willingness towards getting COVID-19 vaccination. The aim of the study was to assess reasons for the apprehension if present towards taking the COVID-19 vaccines among medical students and to spread awareness about the ongoing issue.

Methods: This was a prospective, cross sectional, survey-based study which was conducted at Surat Municipal Institute of Medical Education and Research (SMIMER), Surat, Gujarat, India. Questionnaire was distributed among medical students during lectures and exam going students were sent Google form link. Data collection was done from February to March 2021, and 550 students submitted the forms.

Results: While $34.9 \%$ students had taken the vaccine voluntarily, category I (acceptance group); $18.2 \%$ students were initially hesitant to take the vaccine, but later took it, category II (hesitant group); the frequency increased to $46.9 \%$ students who are still hesitant and have not taken the vaccine, category III (refusal group). Top reasons for hesitancy were: concern regarding adverse events (69\%), safety (60\%) and lack of scientific data (27\%) provided for the vaccines. Conclusions: This study revealed that there was lack of knowledge and positive attitude towards the COVID-19 vaccines among the non-vaccinated students. This evaluation has guided the importance and the need of targeted educational program to address the knowledge gap.
\end{abstract}

Keywords: COVID-19 vaccines, Undergraduate, Medical students, Hesitancy

\section{INTRODUCTION}

The pandemic of corona virus disease 2019 (COVID-19) has caused an unprecedented public health burden in several countries across the globe. ${ }^{1}$ According to the data received by WHO from national authorities, as of $9^{\text {th }}$ May 2021, India continues to account for 95\% of COVID-19 cases and $93 \%$ of deaths in the South-East Asia Region, as well as $50 \%$ of global cases and $30 \%$ of global deaths. ${ }^{2}$ For all of the public health initiatives in place, including behavioural changes such as using masks and hand sanitization, therapeutic treatments such as antiviral drugs and most importantly safe and effective vaccinations seem to be the only way to prevent the pandemic from spreading. Despite the fact that phase three clinical trials were not completed for 'Made in India' vaccines, Covishield and Covaxin, were approved for restricted emergency use as part of control measures taken against COVID-19. The National vaccination drive in India began on $16^{\text {th }}$ January 2021 , across 3,006 vaccination centres giving priority to health care workers and medical students across India. ${ }^{3}$ In the first three days, $6,31,417$ people were vaccinated. Of these, $0.18 \%$ reported side-effects and nine people $(0.002 \%)$ were admitted to hospitals for observation and 
treatment. ${ }^{4}$ There is concern that the vaccine drive is being slowed down by low turnout, due to a combination of concerns about the safety of the vaccine, technical problems with the software used, and misinformation. ${ }^{4}$

The $21^{\text {st }}$ century vaccination landscape is characterized by unprecedented access to information, rising levels of vaccine hesitancy among patients and healthcare professionals (HCPs) such that vaccine hesitance has been included in the top 10 threats to global health by the WHO. ${ }^{5}$ Medical students are among the group of frontline healthcare providers likely to be exposed to COVID-19 patients. $^{6}$ It is important to achieve high COVID-19 vaccination coverage rates in this group as soon as a vaccine is available. ${ }^{6}$

As future healthcare providers, they will be entrusted with providing vaccine recommendations and counselling vaccine-hesitant patients. ${ }^{6}$ Hence, a survey needs to be carried out to investigate reasons for their apprehensions and design a systemic approach to overcome vaccine hesitancy. COVID-19 vaccine drives in India will depend upon how well the issue of vaccine hesitancy is tackled.

\section{METHODS}

A prospective, cross sectional, survey-based study was conducted in targeted population of undergraduate medical students of tertiary care hospital, Surat, Gujarat, India for the duration of one month, February- March 2021. The sample size collected for this study was based upon the responses received within the data collection period. Those students from SMIMER medical college who were not willing to take part in the survey as well as those who were under 18 years of age, therefore not eligible for the vaccine, were excluded from the study.

The questionnaire was self-developed, semi-structured, and pre-validated by the authors before administering the same to the participants. Examination going students were sent online Google form link and students attending college were given questionnaire handouts which were to be filled. A written informed consent was attached with the questionnaire, available both in English and Guajarati, and was presented to the students before they began the survey.

Additionally, in the Google form link sent to examination going students, it was informed to them that participation in the survey will be considered as positive consent for the study. The consent form included details about the purpose of the study, confidentiality rights, the voluntary nature of involvement, and the survey procedure. Permission was obtained from the Institutional Ethics Committee of SMIMER- Surat, India before the commencement of study.

Statistical analysis was done using descriptive statistics. Since some of the questions had multiple responses, sum of the percentage did not always add up to $100 \%$.

\section{Questionnaire}

The questionnaire was formed in a pre-designed, semistructured pattern which composed of eight questions with some follow-on questions. The questionnaire included closed ended questions, open ended questions and multiple-choice questions with predefined answers offering respondents the possibility to choose. ${ }^{7}$

The questionnaire consisted of four sections which assessed mainly four aspects of the students: (a) demographic characteristics; (b) current knowledge about the COVID-19 vaccines; (c) perceived likelihood of taking the COVID-19 vaccines; and (d) general attitudes and perception of vaccines.

The mass vaccination drive in India started on 16th January, 2021, and first round was open for all the doctors, nurses and undergraduate medical students, at SMIMER Medical College, therefore, students had started taking the vaccine. Considering that scenario, the questionnaire was planned out in such a way that those students who have taken the vaccine and those students who have not taken the vaccine both could participate in the survey.

Students were asked whether they were vaccinated or not. Based on the answer to that question, they had to select the category they best fit into and further questions were set accordingly.

Three Categories were formed as follows- (a) category 1: I have taken the vaccine voluntarily (acceptance); (b) category 2: I was initially hesitant, but later took the vaccine (hesitant); (c) category 3: I have not taken the vaccine (refusal). Section one covered the demographic details such as name, age, gender, academic year, and date. Section two assessed the awareness of vaccination program, source of information concerning COVID-19 vaccinations, and response for contracting Corona virus.

Section three covered the likelihood of taking the COVID19 vaccines and accordingly selecting one of the categories: Acceptance, hesitant, or refusal group they best fit into. Specific sub questions under each category were asked to know the determinants of their decision of accepting, hesitating, and refusing COVID-19 vaccine. Section four assessed student's attitude and perception towards 'Made in India' vaccines, and USA and UK vaccines.

Likelihood of recommending vaccines to others as well as accounting their views and opinions on how the vaccine hesitancy in Indian population could have been avoided was also included in our study.

\section{RESULTS}

A total of 550 medical students had responded to the survey. Among the 391 students attending college had filled the survey out of which 17 students were excluded 
from the survey because they were under age, hence were not eligible to take the vaccine.

On the other hand, 176 university examination going students responded through Google form link. As a result, our sample size summed up to be 550. To prevent incomplete and missing results of responses through google form, the majority of the questions were marked as necessary to be answered.

Individual Google form responses were checked by the principal investigator to avoid double entry of the data.

\section{Demographic characteristics}

In Table 1, age group (years): 18-19 $(\mathrm{N}=266)(48.4 \%)$; $20-21 \quad(\mathrm{~N}=232) \quad(42.2 \%) ; 22-23 \quad(\mathrm{~N}=43) \quad(78 \%) ; 24-25$ $(\mathrm{N}=7)(1.3 \%)$. Majority of the participant students were females $356(64.7 \%)$ as compared to males 194 (35.3\%).

MBBS students from all four years were either given the questionnaire or were sent the Google form link.

Responses are as follow: $178(32.4 \%) \mathrm{I}^{\text {st }}$ year, $235(42.7 \%)$ $\mathrm{II}^{\text {nd }}$ year, $46(8.4 \%) \mathrm{III}^{1 \mathrm{st}}$, and $91(16.5 \%) \mathrm{III}^{2 \mathrm{nd}}$ responded.

Table 1: Demographic characteristics.

\begin{tabular}{|lll|}
\hline Characters & $\begin{array}{l}\text { Frequency } \\
(\mathbf{N}=550)\end{array}$ & $\begin{array}{l}\text { Percent } \\
(\%)\end{array}$ \\
\hline Age (years) & & \\
\hline $18-19$ & 266 & 48.4 \\
\hline $20-21$ & 232 & 42.4 \\
\hline $22-23$ & 47 & 7 \\
\hline $24-25$ & 7 & 1.3 \\
\hline Gender & & \\
\hline Male & 194 & 35.3 \\
\hline Female & 356 & 64.7 \\
\hline MBBS year & & \\
\hline I $^{\text {st }}$ & 178 & 32.4 \\
\hline II $^{\text {nd }}$ & 235 & 42.7 \\
\hline III $^{1 \text { st }}$ & 46 & 8.4 \\
\hline III $^{2 n d}$ & 91 & 16.5 \\
\hline
\end{tabular}

\section{Current knowledge about the COVID-19 vaccines}

Out of 550 students, 42 students $(7.5 \%)$ had tested COVID-19 positive as compared to 508 students $(92.5 \%)$ tested negative for the novel corona virus infection.

All the students, (100\%) were aware of the ongoing COVID-19 vaccination program in India.

Student's sources of information regarding COVID-19 vaccinations, in descending order, were: social media $(61.5 \%)$, news channels $(55.8 \%)$, and college professors (43.3\%), friends/family (39.8\%), doctors (37.8\%), newspapers $(34.4 \%)$, and authorised government website (22\%) (Table 2).
Table 2: Sources of information preferred for coronavirus.

\begin{tabular}{|lll|}
\hline Sources & $\begin{array}{l}\text { Frequency } \\
(\mathbf{N}=550)\end{array}$ & $\begin{array}{l}\text { Percent } \\
(\%)\end{array}$ \\
\hline $\begin{array}{l}\text { Authentic government } \\
\text { website }\end{array}$ & 121 & 22 \\
\hline Social media & 338 & 61.5 \\
\hline News channels & 307 & 55.8 \\
\hline Newspapers & 189 & 34.4 \\
\hline Friends/family & 219 & 39.8 \\
\hline Doctors & 208 & 37.8 \\
\hline College professors & 238 & 43.3 \\
\hline
\end{tabular}

\section{Perceived likelihood of taking the COVID-19 vaccine}

Among the 550 students, $292(52.9 \%)$ got vaccinated compared to $258(47.1 \%)$ who did not get vaccinated.

Category wise distribution showed that 192 (34.9\%) students belonged to category I (acceptance group), 100 (18.2\%) students belonged to category II (hesitant group), while $258(46.9 \%)$ students belonged to category III (refusal group) (Table 3).

Table 3: Survey response for category wise selection.

\begin{tabular}{|lll|}
\hline Categories & $\begin{array}{l}\text { Frequency } \\
(\mathbf{N}=550)\end{array}$ & $\begin{array}{l}\text { Percent } \\
(\%)\end{array}$ \\
\hline $\begin{array}{l}\text { Category I: acceptance } \\
\text { I have taken the vaccine } \\
\text { voluntarily }\end{array}$ & 192 & 35.3 \\
\hline $\begin{array}{l}\text { Category II: hesitant } \\
\text { I was initially hesitant, } \\
\text { but later took the } \\
\text { vaccine }\end{array}$ & 100 & 17.8 \\
$\begin{array}{l}\text { Category III: refusal } \\
\text { I have not taken the } \\
\text { vaccine }\end{array}$ & 258 & 46.9 \\
\hline
\end{tabular}

Furthermore, sub questions were asked under each category to know the specific reasons for their selected category choice. Additionally, an open space was also provided in each sub questions for students to elaborate and express their distinctive view-points.

Multiple options were allowed to be ticked hence the total of percentage did not always add up to $100 \%$.

In category I (acceptance group) $(\mathrm{N}=192)$, the factors which influenced their decision on getting vaccinated, from descending order were: (a) positive attitude towards the vaccines $(56.5 \%)$, (b) trusting the information receiving from the public health experts $(43.5 \%)$, (c) uncertainty about the future $(42.5 \%)$, (d) recommendation from known doctors $(34.7 \%)$, (e) not having contacted COVID-19 infection (21.8\%), and (f) peer pressure $(0.5 \%)$ (Table 4). In category II (hesitant group) ( $\mathrm{N}=100)$ : Students choosing this category were initially hesitant to 
take the vaccine but later took it. Therefore, two subquestions were asked.

Firstly, responses for the reasons of their initial apprehensions towards getting vaccinated, in descending order, were: (a) concerned about serious side effects from COVID-19 vaccination (69\%), (b) concerned about the safety of the COVID-19 vaccines $(60 \%)$, (c) lack of scientific data provided for the vaccines $(27 \%)$, (d) belief that the COVID-19 vaccine may not be effective (24\%), (e) hesitancy among family members (20\%), (f) misinformation created panic $(20 \%)$, (g) not getting the option to choose between the 'Made in India' vaccine (11\%), (h) delay due to ongoing university examinations $(3 \%)$, and (i) history of anaphylaxis (1\%) (Table 5).

Secondly, despite the hesitancy, their reasons for considering to take the vaccines, in descending order, were: (a) recommendation by doctors/college professors/healthcare workers $(50 \%)$, (b) motivated from seeing the doctors and healthcare workers taking the vaccine $(45 \%)$, (c) uncertainty about the ongoing pandemic $(34 \%)$, (d) encouragement from family members $(16 \%)$, (e) have not contacted the virus (16\%), and (f) peer pressure (10\%) (Table 6).

All the students from both category I and II, (N=292) were willing to take the second dose.

In category III (refusal group) $(\mathrm{N}=258)$, reasons for not taking the vaccine, in descending order, were as follows: (a) waiting for a better crafted vaccine with fewer side effects $(62.4 \%)$, (b) need more scientific data to be convinced $(26.4 \%)$, (c) having better immunity to fight the infection $(24 \%)$, (d) $1^{\text {st }}$ round of vaccination drive showed side effects $(19.4 \%)$, (e) elderly should be prioritized (17.8\%), (f) friends/colleagues not taking the vaccine (11.2\%), (g) developed antibodies without contacting the virus $(6.2 \%)$, (h) not getting the option to choose between the 'Made in India' vaccines (5.4\%), (i) rapid development of vaccine $(4.7 \%)$, and (j) developed the antibodies after contacting the virus $(3.9 \%)$. In the open space which was provided, three common reasons cited by the students were (a) took hepatitis B vaccine $(2.4 \%)$, (b) delayed due to ongoing university exams (2\%), and (c) hypersensitivity reaction $(1.4 \%)$ (Table 7$)$.

Table 4: Survey response for COVID-19 vaccine acceptance group (category I).

\begin{tabular}{|c|c|c|}
\hline Category I: Which factor/s influenced to get vaccinated? & $\begin{array}{l}\text { Frequency } \\
(\mathrm{N}=192)\end{array}$ & Percent $(\%)$ \\
\hline Positive attitude towards the vaccines & 109 & 56.5 \\
\hline Trusting the information receiving from the public health experts & 85 & 43.5 \\
\hline Uncertainty about the future & 81 & 42.5 \\
\hline Recommendation from known doctors & 67 & 34.7 \\
\hline Not having contracted COVID-19 infection & 42 & 21.8 \\
\hline Peer pressure & 1 & 0.5 \\
\hline
\end{tabular}

Table 5: Survey response for COVID-19 vaccine hesitant group (category II).

\begin{tabular}{|c|c|c|}
\hline Category II: Why were you initially apprehensive towards getting vaccinated? & $\begin{array}{l}\text { Frequency } \\
(\mathrm{N}=\mathbf{1 0 0})\end{array}$ & Percent $(\%)$ \\
\hline Concerned about serious side effects from COVID-19 vaccination & 69 & 69 \\
\hline Concerned about the safety of the COVID-19 vaccines & 60 & 60 \\
\hline Lack of scientific data provided for the vaccines & 27 & 27 \\
\hline Belief that the COVID-19 vaccine may not be effective & 24 & 24 \\
\hline Hesitancy among family members & 20 & 20 \\
\hline Misinformation created panic & 20 & 20 \\
\hline Not getting the option to choose between 'Made in India' vaccines available & 11 & 11 \\
\hline Delayed due to ongoing university examinations & 3 & 3 \\
\hline History of anaphylaxis & 1 & 1 \\
\hline
\end{tabular}

Table 6: Survey response for COVID-19 vaccine hesitant group (category II).

\begin{tabular}{|c|c|c|}
\hline Category II: Despite the hesitancy, why did you consider taking the vaccine? & $\begin{array}{l}\text { Frequency } \\
(\mathbf{N}=\mathbf{1 0 0})\end{array}$ & Percent $(\%)$ \\
\hline Recommendation from doctors/college professors/healthcare workers & 50 & 50 \\
\hline Motivated from seeing the doctors and healthcare workers taking the vaccine & 45 & 45 \\
\hline Uncertainty about the ongoing pandemic & 34 & 34 \\
\hline Encouragement from family members & 16 & 16 \\
\hline Have not contracted the virus & 16 & 16 \\
\hline
\end{tabular}


Table 7: Survey response for COVID-19 vaccine refusal group (category III).

\begin{tabular}{|c|c|c|}
\hline Category III: Why have you not taken the vaccine? & $\begin{array}{l}\text { Frequency } \\
(\mathrm{N}=\mathbf{2 5 8})\end{array}$ & Percent $(\%)$ \\
\hline Waiting for a better crafted vaccination with fewer side effects & 161 & 62.4 \\
\hline Need more scientific data to be convinced & 68 & 26.4 \\
\hline Have better immunity to fight the infection & 62 & 24 \\
\hline $1^{\text {st }}$ round of vaccination drive showed side effects & 50 & 19.4 \\
\hline Elderly should be prioritized & 46 & 17.8 \\
\hline Friends and colleagues are not taking the vaccine & 29 & 11.2 \\
\hline Not contracted COVID-19 infection but developed antibodies & 16 & 6.2 \\
\hline Between the two vaccines available, not getting the option to choose & 14 & 5.4 \\
\hline Vaccine is developed too quickly & 12 & 4.7 \\
\hline Have contracted COVID-19 infection hence developed the antibodies & 10 & 3.9 \\
\hline Recently taken hepatitis $B$ vaccine & 6 & 2.4 \\
\hline Delaying due to ongoing university exams & 5 & 2 \\
\hline Hypersensitivity reaction & 4 & 1.5 \\
\hline
\end{tabular}

\section{General attitudes and perception of vaccine}

While $180(32.9 \%)$ students would rather take Pfizer (BioTech)/Oxford (AstraZeneca)/Moderna vaccine which are given in the USA and UK instead of Covishield/ Covaxin which is given in India, 370 (67.1\%) showed positive response towards 'Made in India vaccines'. Between the two 'Made in India' vaccines available, Covishield and Covaxin, if the students had the option to choose the vaccine they want, 407 (74\%) preferred Covishield, $103(18.7 \%)$ preferred Covaxin, whereas 40 $(7.3 \%)$ said they would not choose either one (Table 8).
$508(92.4 \%)$ students would recommend others to take the vaccine while remaining $42(7.6 \%)$ were not willing to recommend.

Opinion of students was asked regarding what could have been done to avoid vaccine hesitancy in Indian population.

Responses were as follows: 364 (66.2\%) suggested More awareness, campaigns/drive should be done by the government/corporation. $308(56.2 \%)$ said education for public and $283(51.5 \%)$ asked for more scientific data to be provided by an authentic source (Table 9).

Table 8: Preferred 'Made in India' COVID-19 vaccine $(\mathrm{N}=550)$.

\begin{tabular}{|lll|}
\hline Preferred 'Made in India' COVID-19 vaccine & $\begin{array}{l}\text { Frequency } \\
(\mathbf{N}=550)\end{array}$ & Percent $(\%)$ \\
\hline Covishield & 407 & 74 \\
\hline Covaxin & 102 & 18.7 \\
\hline None & 40 & 7.3 \\
\hline
\end{tabular}

Table 9: Implications to avoid future vaccine hesitancy.

\begin{tabular}{|c|c|c|}
\hline $\begin{array}{l}\text { How do you feel the vaccine hesitancy in Indian population could have been } \\
\text { avoided? }\end{array}$ & $\begin{array}{l}\text { Frequency } \\
(\mathbf{N}=\mathbf{5 5 0})\end{array}$ & Percent $(\%)$ \\
\hline $\begin{array}{l}\text { More awareness, campaigns/drive should be done by the government/ } \\
\text { corporation }\end{array}$ & 364 & 66.2 \\
\hline Education for public & 308 & 56.2 \\
\hline More scientific data provided by an authentic source & 285 & 51.8 \\
\hline
\end{tabular}

\section{DISCUSSION}

\section{Current knowledge about COVID-19 vaccines}

The millennial generation is known for their technological skills and embracing the digital life, especially promoted during the lockdown, therefore social media platforms could have played a major role to influence their perception towards corona virus and its vaccination. Barello et al., 2020 stated in one of their preliminary findings that vaccination attitude is influenced by the students' level of health knowledge. ${ }^{8}$ In the present study, most common medium from which students acquired knowledge regarding COVID-19 were: social media $(61.6 \%)$, news channels $(55.8 \%)$, and college professors (43.3\%). Least source of knowledge came from authorized government website (22\%). A similar finding was reported by Saied et al, 2021 in which the author has noted social media, and healthcare providers to be the primary sources of information for COVID-19. Meanwhile, magazines and newspapers were the least. ${ }^{9}$ The same is supported by the finding by Qiao et al, 2020 in which the health agencies 
$(57.7 \%)$, mass media $(49.5 \%)$, and personal social networks $(40.5 \%)$ were the leading source for COVID-19 vaccine information. ${ }^{10}$ Hence it can be noted that vaccine hesitancy could have been exacerbated by the spread of misinformation through social media and mass media platforms.

\section{Perceived likelihood of taking the COVID-19 vaccine}

In spite of being at a high-level risk for contracting the infection, majority of the students were still hesitant to take the vaccine. It was observed that $92.5 \%$ of students had not been infected with COVID-19 and $7.5 \%$ of students had tested positive with COVID-19 infections. Our results matched with the finding by Saied et al, 2021 in which more than half of the respondents i.e.; $56.4 \%$ were not infected with COVID-19, and only $4.4 \%$ had confirmed infection. ${ }^{9}$ This result was in consistent with Lucia et al, 2020 in which more than 2 of 10 students were vaccinehesitant despite self-perception of elevated risk of exposure to COVID-19 infection. ${ }^{6}$ Conversely this finding contradicts research done in the past which showed the key driver of vaccination intentions was perceived from one's risk (of contracting influenza and of suffering from vaccine adverse events) Betsch and Wicker et al. ${ }^{11}$

The present study also observed that while $35.3 \%$ students had voluntarily taken the vaccine and $17.8 \%$ of the students were initially hesitant but later took the vaccine, the frequency increased to $46.9 \%$ of the students of category III, who had not taken the vaccine. Our results corresponded with the findings of Said et al, 2021 in which $35 \%$ of the students accepted the COVID-19 vaccination, $46 \%$ were hesitant, and 19\% refused among Egyptian medical students. ${ }^{9}$ On the contrary, results differed in a study conducted by Qiao et al, 2020 in which $60.6 \%$ students were in the acceptance group, $15.1 \%$ students were hesitant and $24.3 \%$ belonged to the refusal group among college students in South Carolina. ${ }^{10}$ Furthermore, in a study conducted by Lucia et al., 2020 nearly onequarter of the students of Southeast Michigan was hesitant to be vaccinated. ${ }^{6}$ This shows that acceptance rate among the medical students of Surat city in particular is lower than the other countries and this is a major concern in the ongoing attempts to control the latest COVID-19 pandemic.

Undergraduate medical students in Gujarat particularly, were approached to help in this unsighted situation due to lack of frontline workers. Therefore, after assessing the current situation, students should be well prepared beforehand to tackle future waves, peaks, and pandemic. In fact, study by Barello et al, 2020 and Stokes et al, 2020 stated that medical schools in countries such as England as well as in United States prepare students to help medical teams efficiently, that's why, they should be protected and vaccinated, as vaccination of healthcare workers and students is an important step in preventing health-related infections from close contact with high-risk patients. ${ }^{8,12}$ The students in the acceptance category can play an important role in encouraging other hesitant students as well as general public to take the vaccine.

Findings reported by Saied et al, 2021 in which most participants reported having concerns about effectiveness, safety, and adverse effects about the vaccine. ${ }^{9}$ In another study conducted by Sun et al, 2020 their result also showed that $88.91 \%$ participants endorsed concerns about COVID-19 vaccine side effects. ${ }^{13}$ The above studies support the findings of the present study. Many people who are hesitant about vaccination may consider it if they are reassured and given reliable evidence that the vaccine is safe and effective.

Despite the hesitancy, $50 \%$ of the students from category II took the vaccination on recommendation from doctors/ college professors/healthcare workers, while $45 \%$ students got inspired from seeing the doctors and healthcare workers taking the vaccine. $34 \%$ cited that the pandemic is not going to end soon, better to be safe than sorry.

Among the refusal group, category III students, $2.4 \%$ had recently taken hepatitis $\mathrm{B}$ vaccine and $2 \%$ cited ongoing exam university for delaying or not taking the vaccine. This depicts that some students falling in category III are not actually refusing the vaccine but are delaying the vaccination due to short term adverse events which could disrupt them during the exams period. Evidence suggests that working on building confidence in COVID-19 vaccines is crucial. Lucia et al, 2020 underlined the contributing factors to vaccine hesitancy in this age group. ${ }^{6}$ Concerns about serious vaccine side effects and lack of trust in the information received from public health experts and the fact that need for transparency and ability to answer concerns about speedy development of the vaccine should be addressed.

\section{General attitude and perception of vaccines}

It was observed that $32.9 \%$ students preferred to take Pfizer (BioTech)/Oxford (AstraZeneca)/Moderna vaccine instead of 'Made in India' vaccine. On the contrary, $67.1 \%$ students supported the vision, 'Atmanirbhar Bharat', of our honourable Prime Minister Narendra Modiji, and said that even if they had an option to take the vaccines given in the US and UK, they would still take the 'Made in India' vaccines.

Among these students, $74 \%$ students preferred to take Covishield, and $18.7 \%$ preferred Covaxin if they were given an option to choose the vaccine they would. Evidence suggests that between the two vaccines, only Covishield had released the safety and phase 3 efficacy data publically through a scientific publication of the parent AstraZeneca vaccines. ${ }^{14}$ While it was only recently, $3^{\text {rd }}$ March 2021, that the announcement was made public about the $81 \%$ efficacy of Covaxin, however the scientific report is yet to be published. ${ }^{15}$ Hence, availability of scientific data is significant to gain the trust of public for mass vaccination programs. 
Despite the hesitancy and majority of the student not taken the vaccine yet, they would still recommend others to take the vaccination. To overcome the vaccine hesitancy among Indian population, students suggested that the government/ corporation should host more awareness, campaigns and vaccination drives along with education for the public. More importantly, enough scientific data should be provided by an authentic source. Lessons learned from previous infectious disease outbreaks and public health emergencies, including HIV, H1N1, SARS, MERS and Ebola; remind us that trusted sources of information and guidance are fundamental to disease control. ${ }^{16}$

\section{Limitations}

Our study was limited to a single medical college of Surat. Moreover, due to the ongoing university examinations, there was low response rate through online mode of data collection hence this may impact the generalizability.

\section{CONCLUSION}

Vaccine apprehension is nothing new; it has existed in all global immunisation programmes, whether it was vaccination for smallpox, cholera, measles, or influenza, and COVID-19 is of no exception. However, the uncertainty over a vaccine, which is our only source to fight the deadly pandemic that has already taken the lives of more than twenty-three million people worldwide, is indeed a source of profound concern. In order to plan an effective post-pandemic approach, it is essential to first consider the students' knowledge, attitude, and perception toward the COVID-19 vaccines and then work to increase their acceptance.

This study revealed that there was lack of knowledge and positive attitude towards the COVID-19 vaccines among the non-vaccinated students. Lesson should be learned that early roll out of vaccines lacking in scientific data will definitely increase the concerns regarding adverse events and safety of the vaccine as well as rise in vaccine hesitancy. Hence, this evaluation has guided us in showing the importance and need of targeted educational interventions to address the knowledge gaps and prepare students to discuss and implement about the ways to avoid vaccine hesitancy problems amongst the Indian population for the future pandemics.

\section{ACKNOWLEDGEMENTS}

We appreciate the guidance and support given by the respected faculty members of Pharmacology Department of SMIMER, Surat. We would like to appreciate medical students of SMIMER Medical College who participated in the survey.

\footnotetext{
Funding: No funding sources Conflict of interest: None declared

Ethical approval: The study was approved by the Institutional Ethics Committee
}

\section{REFERENCES}

1. Shrivastava S, Shrivastava P. Corona Virus Disease 2019 Pandemic: The Necessity for Outbreak Readiness and Response Plan in Prison Settings. MAMC J Med Sci. 2020;6(2):121.

2. WHO. Weekly epidemiological update on COVID-19, 2021. Available at: https://www.who.int/publications/m/item/weeklyepid emiological-update-on-COVID-19. Accessed on 11 May 2021.

3. Patil P. Fight Against Covid, 2021. Available at: https://www.fightagainstcovid.net/. Accessed on 23 May 2021.

4. Wiot F, Shirley J, Prugnola A, Pasquale A, Philip R. Challenges facing vaccinators in the 21 st century: results from a focus group qualitative study. Hum Vaccin Immunother. 2019;15(12):2806-15.

5. Lucia VC, Kelekar A, Afonso NM. COVID-19 vaccine hesitancy among medical students. J Public Health. 2020;230.

6. Ministerio De Aseuntos Exteriores De Cooperation. Euromed Survey Of Experts And Actors Violent Extremism In The Euromediterranean Region, 2019. Available at: https://opev.org/wpcontent/uploads/2019/10/IEMed.-EuroMed-Survey2017. Accessed on 23 May 2021.

7. Kvasyuk EN. Development of professional competence of future foreign language teachers in inclusive education through profession-based volunteering. Kvasyuk EN. SHS Web of Conferences. 2020;87:27.

8. Barello S, Nania T, Dellafiore F, Graffigna G, Caruso R. 'Vaccine hesitancy' among university students in Italy during the COVID-19 pandemic. Eur J Epidemiol. 2020;35(8):781-3.

9. Saied SM, Saied EM, Kabbash IA, Abdo SAE. Vaccine hesitancy: Beliefs and barriers associated with COVID-19 vaccination among Egyptian medical students. J Med Virol. 2021;93(7):4280-91.

10. Qiao S, Friedman DB, Tam CC, Zeng C, Li X. Vaccine acceptance among college students in South Carolina: Do information sources and trust in information make a difference?. MedRxiv. 2020;20242982.

11. Betsch C, Wicker S. E-health use, vaccination knowledge and perception of own risk: drivers of vaccination uptake in medical students. Vaccine. 2012;30(6):1143-8.

12. Stokes DC. Senior Medical Students in the COVID-19 Response: An Opportunity to Be Proactive. Acad Emerg Med. 2020;27(4):343-5.

13. Sun S, Lin D, Operario D. Interest in COVID-19 vaccine trials participation among young adults in China: Willingness, reasons for hesitancy, and demographic and psychosocial determinants. MedRxiv. 2020;20152678.

14. Sah R, Shrestha S, Mehta R, Sah SK, Raaban AA, Dharma K, et al. AZD1222 (Covishield) vaccination 
for COVID-19: Experiences, challenges, and solutions in Nepal. Travel Med Infect Dis. 2021;40:101989.

15. Bharat Biotech. Bharat Biotech Announces Phase 3 Results of COVAXIN®: India's First COVID-19 Vaccine Demonstrates Interim Clinical Efficacy of 81\%, 2021. Available at: https://www.bharatbiotech.com/images/press/covaxin -phase3-efficacy-results. Accessed on 23 May 2021.

16. Lazarus JV, Ratzan SC, Palayew A, Gostin LO, Larson HJ, Rabin K, et al. A global survey of potential acceptance of a COVID-19 vaccine. Nat Med. $2021 ; 27(2): 225-8$.

Cite this article as: Shah AY, Banzal N, Mehta C, Desai A. Assessment of COVID-19 vaccine hesitancy among undergraduate medical students of a tertiary care teaching hospital, Surat: a source of profound concern. Int J Basic Clin Pharmacol 2021;10:984-91. 